\title{
A monitoria acadêmica como aliada no processo de formação teórico- prática de licenciandos em ciências biológicas
}

\author{
Academic tutoringin the process of theoretical-practical training in teacher \\ training on biological sciences
}

\author{
Maria Camila Braga ${ }^{1}$ \\ Herikson Araújo de Freitas ${ }^{2}$
}

\begin{abstract}
Resumo
Este estudo analisa, sob a perspectiva dos envolvidos com a monitoria acadêmica (monitores e orientadores), o significado atribuído a este instrumento de formação no Curso de Licenciatura em Ciências Biológicas do IFCE/Campus Acaraú. Trata-se de pesquisa de abordagem qualitativa, classificada como descritiva e de levantamento. $O$ cenário foi o IFCE/Campus Acaraú e os sujeitos os ex-monitores de disciplinas constantes da matriz curricular do referido curso e seus respectivos orientadores. Para a obtenção dos dados, foi utilizado o questionário como técnica de coleta, aplicado nos meses de agosto e setembro de 2019. Os resultados apontaram para o reconhecimento, da parte dos sujeitos, de que a monitoria acadêmica tem reflexos significativos no processo de ensino-aprendizagem, caracterizando-a como um suporte ao trabalho pedagógico, através do desenvolvimento de atividades que contribuem no aprendizado dos alunos. No entanto, para o alcance máximo do seu potencial formativo, lacunas precisam ser sanadas, em se tratando de experiências desenvolvidas no campo da formação inicial.
\end{abstract}

Palavras-chave: Iniciação à Docência. Ensino e Aprendizagem. Formação Inicial. Biologia.

\begin{abstract}
This study analyze from the perspective of those involved with academic monitoring (monitors and advisors) the meaning attributed to this training instrument in the Biological Sciences Degree Course at IFCE/Campus Acaraú. This is a qualitative approach research, classification as descriptive and survey. The scenario was the IFCE/Campus Acaraú and the subjects were the ex-monitors of subjects included in the curricular matrix of that course and their respective supervisors. To obtain the data, the questionnaire was used as a collection technique, applied in the months of August and September 2019. The results pointed to the recognition, on the part of the subjects, that the academic monitoring has significant reflexes in the teaching-learning process, characterizing itas a support for pedagogical work, through the development of activities that contribute to student learning. Nonetheless, for the maximum reach of its formative potential, gaps need to be solved, in terms of developed experiences in the field of initial training.

\footnotetext{
1 Instituto Federal de Educação, Ciências e Tecnologia do Ceará (IFCE/Campus Acaraú). Graduada em licenciatura em Ciências Biológicas. E-mail: maria.camila.braga@gmail

${ }^{2}$ Instituto Federal de Educação, Ciência e Tecnologia do Ceará (IFCE/CAMPUS ACARAÚ). Mestre. Professor da Área de Ensino de Ciências e Biologia. E-mail: herikson.freitas@ifce.edu.br
} 
Key words: Initiation to Teaching, Teaching and learning, Initial Formation. Biology.

\section{Introdução}

A monitoria acadêmica, em seu sentido mais amplo, pode ser entendida como um instrumento de ensino e aprendizagem, cujo principal propósito é auxiliar nos processos de compreensão e produção de conhecimentos, em âmbito universitário, contribuindo assim para a formação integrada do aluno enquanto monitor.

Esse entendimento pode ser atestado na perspectiva de Lira et al. (2015), que ressalta ser a monitoria um mecanismo que auxilia nos processos de ensinoaprendizagem, durante a graduação, favorecendo na preparação para a formação docente. Para Cavalcante et al. (2019), essa atividade é de grande importância, visto que tem o intuito de estimular os alunos para o exercício da docência, possibilitando um contato direto com os discentes e uma melhor compreensão das dificuldades apresentadas por eles.

Desse modo, a monitoria, dentro do sistema universitário, se apresenta como um programa incentivador que promove uma maior especialização, além de um aperfeiçoamento da aprendizagem para a prática docente no ensino superior (SOUZA; NERY, 2016). Dado seu lócus de execução, seu caráter científico e prático contempla as modalidades de ensino, pesquisa e extensão das universidades, contribuindo significativamente para a formação inicial de futuros professores (DIAS, 2012).

Não obstante às suas potencialidades enquanto instrumento formativo, é importante considerar que a monitoria pode ter sua função desvirtuada e, em decorrência, apresentar-se como obstáculo e causadora de efeito inverso no processo de ensino e aprendizagem.

Para Nunes (2007), uma primeira observação se faz em função da comprovação de que nem toda instituição valoriza a monitoria como lhe é devido. A ânsia pela pesquisa que domina o cenário acadêmico reflete-se na oferta de bolsas para estudantes de graduação, pelos órgãos financiadores, apenas para iniciação científica. Assim, os programas de monitoria acadêmica que dependem do financiamento da própria Instituição de Ensino Superior (IES) para se sustentar, acabam por sofrer consequências, uma vez que estes geralmente são muito limitados.

Ademais, não se pode manter o monitor restrito às funções de ensino. É importante que estes tenham uma formação mais abrangente e as IES devem se comprometer com esta formação. Na prática, algumas vezes, observam-se certos desvios, como nos casos em que o monitor se torna apenas um simples "tarefeiro", executando tarefas muito simples como buscar diários, coletar apagador e giz, transcrever notas, receber trabalhos de alunos. Outras vezes, situações mais graves ocorrem, quando o professor orientador "acredita" que o monitor é seu empregado, 
desconsiderando por completo sua função de formador daquele aluno (NUNES, 2007).

Dessa forma, o presente artigo objetiva analisar, sob a perspectiva dos envolvidos com a monitoria acadêmica (monitores e orientadores), o significado atribuído a este instrumento de formação no Curso de Licenciatura em Ciências Biológicas do Instituto Federal de Educação, Ciência e Tecnologia do Ceará (IFCE/Campus Acaraú).

A ideia de investigação trazida à tona justifica-se pela necessidade de se promover um melhor entendimento acerca das iniciativas fomentadas pelo IFCE/Campus Acaraú com monitoria acadêmica. Desse modo, pretende-se oportunizar uma compreensão e acesso panorâmico das políticas e programas desenvolvidos, em âmbito institucional, que certamente poderá contribuir na formatação de propostas e ações que repercutam na (re)organização e/ou incentivo às iniciativas desenvolvidas até então.

\section{Metodologia}

A abordagem da pesquisa teve caráter qualitativo que, conforme defendem Lüdke e André (2013), tem dados coletados predominantemente descritivos, partindo da análise do pesquisador e de sua compreensão do todo para a reflexão sobre o que pode ser ou não elucidado, uma vez que a descrição deve possibilitar um diálogo com o objeto. Desse modo, se trabalha com o sentido de inteligência do pesquisador, visto que a preocupação com o processo é muito maior do que com o produto.

Assim, no que se refere aos seus objetivos, o estudo pode ser caracterizado como do tipo descritivo, uma vez que visou "descrever e decodificar os componentes de um sistema complexo de significados" (NEVES, 1996, p.1). No seu particular, os significados foram atribuídos pelos participantes (monitores e respectivos orientadores) ao processo de monitoria acadêmica como instrumento de formação universitária.

No que tange aos procedimentos técnicos adotados, trata-se de uma pesquisa de levantamento, tendo em vista que seu foco foi "promover uma interrogação direta das pessoas cujo comportamento se desejou conhecer" (GIL, 2008, p. 50).

O cenário da pesquisa foi o IFCE/Campus Acaraú e, os sujeitos, os ex-monitores de disciplinas constantes da matriz curricular do Curso de Licenciatura em Ciências Biológicas e seus respectivos orientadores.

Como critério de inclusão, foram mobilizados a participarem do estudo todos os monitores e orientadores que se mantiveram em atividades regulares no Programa Institucional de Monitoria Acadêmica do IFCE/Campus Acaraú, nos anos de 2017 e 2018, contemplados ou não com bolsa remunerada.

Conforme levantamento realizado previamente junto ao Departamento de Ensino do Campus que constitui o cenário pesquisado, foi mobilizado um quantitativo de 10 (dez) monitores, distribuídos da seguinte forma: 08 (oito) voluntários e 01 (um) bolsista com 
atuações em 2017; e 02 (dois) bolsistas com atuações em 2018, tendo um deles atuado também no ano anterior. Dada esta distribuição, justifica-se o quantitativo apontado.

Quanto aos orientadores que também foram mobilizados no estudo, estes somaram 07 (sete) professores vinculados às seguintes disciplinas: Biologia Celular, Botânica de Fanerógamas, Ecologia de Comunidades e conservação, Genética, Química Geral, Zoologia de Cordados, Zoologia de Invertebrados I, Zoologia de Invertebrados II e Microbiologia.

No entanto, considerando a não adesão da totalidade dos sujeitos, dado o caráter voluntário da pesquisa, esta contou, efetivamente, com a participação de 08 (oito) monitores e 05 (cinco) orientadores, correspondendo aos percentuais de $80 \%$ (oitenta por cento) e $71 \%$ (setenta e um por cento) do universo, respectivamente.

Como instrumento de coleta, foi utilizado um questionário cuja composição foi de perguntas abertas acerca do objeto de estudo. O questionário como instrumento de coleta se mostra como uma série ordenada de questionamentos que foram respondidos por escrito pelo informante, sem a presença física do pesquisador no ato do seu preenchimento (GIL, 2008).

A coleta foi realizada no período de agosto a setembro de 2019. Os participantes foram devidamente informados sobre a natureza da pesquisa, bem como sobre os objetivos elencados, ressaltando-se a importância da participação para seu êxito. Juntamente com o questionário, foi colocado, à disposição dos sujeitos, o Termo de Consentimento Livre e Esclarecido (TCLE), documento que foi devidamente assinado e devolvido, no qual ficou ratificada a ciência dos envolvidos em relação aos propósitos fixados na pesquisa e as implicações das suas participações.

A pesquisa foi submetida à apreciação do Comitê de Ética em Pesquisa (CEP) do IFCE e somente teve suas etapas inicializadas após manifestação expressa deste colegiado em parecer favorável à sua realização (Parecer de aprovação $n^{\circ}$ 3.513.596, datado de 17 de agosto de 2019).

Ressalta-se que os princípios éticos deste estudo foram devidamente atendidos, uma vez que sua orientação se estabeleceu em consonância com aquilo que preconiza a Resolução do Conselho Nacional de Saúde/CNS n 510/2016, que trata da ética na pesquisa, na área de Ciências Humanas e Sociais.

A organização dos dados ocorreu por meio da análise dos conteúdos dos questionários, onde foram organizados e apresentados em categorias, de modo a proporcionar o alcance do objetivo da pesquisa.

Desse modo, as categorias temáticas tiveram a seguinte conformação: (1) sentido conferido à monitoria acadêmica pelos envolvidos; (2) nível de clareza em relação às suas atribuições e responsabilidades; (3) experiências significativas, vivenciadas por monitores e orientadores no decurso da monitoria acadêmica; (4) possíveis dificuldades e/ou 
problemáticas enfrentadas com as experiências vivenciadas.

Para efeito de análise, os conteúdos dos questionários foram tratados a partir das respostas obtidas para cada pergunta formulada, cuja interpretação foi realizada com subsídios da literatura relacionada ao problema de pesquisa. Posteriormente, esses dados foram traduzidos pela transcrição de recortes extraídos dos registros dos sujeitos nos questionários, seguidos de discussão apresentada em texto expositivo e analítico.

\section{Resultados e Discussão}

A seguir, serão apresentados os resultados da pesquisa, acompanhados de discussão baseada nos dados coletados juntos aos sujeitos. Os dados estão organizados de forma sistemática, a partir da estruturação das categorias temáticas. A ideia é promover uma aproximação com as informações coletadas nos questionários, revelando os achados em cada categoria analisada, de modo a se possibilitar uma interpretação com subsídio da literatura.

\section{Categoria Temática 1 - Sentido conferido à monitoria acadêmica pelos envolvidos}

Nesta categoria temática, são abordadas as concepções dos monitores ( $M)$ e orientadores $(\mathrm{O})$ sobre o significado atribuído à prática da monitoria, permitindo-se perceber que os participantes consideram esta prática como um método preparatório para futuros professores, à medida que intervém no processo de ensino-aprendizagem dos alunos monitorados. Algumas destas colocações são demonstradas a seguir.

É uma experiência bastante enriquecedora para qualquer aluno que tenha a oportunidade de vivenciá-la. Pois é uma experiência que permite vivenciar mais de perto a prática pedagógica, na ajuda ao professor em suas atividades em buscar uma melhor forma de repassar algum conteúdo por exemplo. Como também na ajuda aos alunos na execução de atividades e saneamento de dúvidas quando possível. M1

Participar da monitoria foi de grande importância para a minha vida acadêmica, pois possibilita vários aspectos positivos como maior aprendizado através da prática, experiência para uma futura profissão, de modo a nos tornar mais preparados a exercer melhor a função atribuída ao logo da vida profissional. $\mathrm{M}_{3}$

Contribuir tanto para o processo de formação do monitor, como ter ajuda para as aulas práticas. Acaba sendo uma via de mão dupla em que todos os envolvidos, inclusive os alunos da disciplina, saem ganhando. 01

A monitoria acadêmica é um programa de aprimoramento do saber docente, na qual o professor orientador pode passar mais detalhes sobre os temas abordados em sua disciplina para o monitor.

Além disso, ressalta-se a importante experiência didática para o monitor, pois no momento da monitoria ele desenvolverá mais os conhecimentos que tinha da disciplina, aprenderá sobre a prática de montagem de aulas práticas didáticas e permitirá que o mesmo desenvolva novas competências e conhecimentos sobre docência no ensino técnico e superior. $\mathrm{O}_{2}$

Constata-se, através dos registros dos envolvidos, que a monitoria acadêmica, no 
que se refere ao sentido atribuído a esta prática, é entendida como um suporte ao trabalho pedagógico, através do desenvolvimento de atividades que contribuem no aprendizado dos alunos, aproximando o acadêmico monitor da prática docente.

De fato, conforme os posicionamentos de Nunes (2007, p. 46), "A monitoria acadêmica tem se mostrado nas Instituições de Educação Superior (IES) como um programa que deve cumprir, principalmente, duas funções: iniciar o aluno na docência de nível superior e contribuir com a melhoria do ensino de graduação"

Portanto, quando inserido no programa, o aluno-monitor, poderá aprofundar conhecimentos junto aos colegas, dentro dos conteúdos da disciplina na qual monitora, através da dinamização e contextualização destes assuntos, desenvolvendo habilidades sociais e intelectuais, na medida em que colabora com o processo de aprendizagem destes alunos. Ao mesmo tempo, também será favorecido com uma ótima experiência que servirá de auxílio para encarar a expectativa de se tornar um futuro docente (BARBOSA; AZEVEDO; OLIVEIRA, 2014).

Nessa mesma perspectiva, Matoso (2014) relata que o privilégio concedido aos alunos que participam do programa é fundamental para o achado, ou não, de sua vocação pela docência, o que impede a formação de profissionais insatisfeitos com a carreira escolhida.

Assim, ao associar as concepções dos sujeitos, nota-se uma coerência e uma aproximação de entendimentos entre monitores e orientadores, respaldados com aquilo que a literatura traz, uma vez que o sentido da monitoria, de fato, estabelece uma relação entre o auxílio exercido no ensino da graduação e a formação inicial dos futuros docentes.

\section{Categoria Temática 2 - Nível de clareza em relação às suas atribuições e responsabilidades}

Nesta categoria temática se analisa o reconhecimento dos sujeitos acerca das suas obrigações a serem cumpridas no exercício da atuação como monitor ou orientador, destacando-se quais atribuições e responsabilidades são consideradas próprias, tanto da monitoria quanto da orientação.

Em unanimidade, todos os monitores destacaram ter clareza sobre suas atribuições e responsabilidades. Para Rabelo et al. (2017), esta clareza se faz necessária para que se evitem a realização de atividades que não sejam da monitoria propriamente dita.

Ao analisar os registros, nota-se que as atividades destacadas pelos monitores, como sendo particulares da monitoria, apresentam relação direta com o suporte exercido no ensino da graduação. A seguir, são explicitadas algumas destas colocações.

Sim. Auxiliar e apoiar tanto o professor quanto os alunos em suas atividades, sejam elas em sala de 
-Revista de Iniciação à Docência, v. , n. , 2021-

Publicação: dezembro, 2021 - ISSN 2525-4332

aula, práticas em laboratório ou em aulas de campo. M1

Sim. Planejamento semanal, momentos para esclarecimento de dúvidas com os discentes, resolução de exercício com os discentes e horários dentro da instituição em que o monitor esteja presente para atender aos discentes. M5

Sim. Ser participativo nas aulas práticas e teóricas, ter tempo disponível para tirar as dúvidas dos alunos, assim como, responsabilidade em estar presente durante meus horários. M7

A parir dos registros, é perceptível que as atividades destacadas pelos sujeitos são favorecedoras no aperfeiçoamento do processo ensino-aprendizagem, uma vez que, através da assistência empregada em determinadas disciplinas, os alunos terão uma maior chance de aprofundar seus conhecimentos.

Para Stefanello; Junho; Beatrici (2017), dentro das carências apresentadas no processo de formação, a monitoria possibilita que os acadêmicos que estão regularmente matriculados, tenham a chance de introduzir-se ao espaço de aprendizagem da sala de aula, desenvolvendo atividades relacionadas aos conteúdos estudados, auxiliando os alunos no processo de construção do conhecimento a partir dos conteúdos trabalhados pelo professor.

Dessa forma, essa prática busca fomentar o aprendizado dos alunos, por meio do compromisso que o aluno-monitor exerce em relação a construção de conhecimento dos demais colegas (GALDINO; ABRANTES, 2019).

Na perspectiva de Pereira (2007), é de responsabilidade do monitor promover uma aproximação do professor com o aluno dentro do contexto de ensino, bem como executar atividades didáticas que auxiliem no melhor entendimento do conteúdo abordado em classe, conforme as dificuldades apresentadas e de modo que obedeça ao grau de conhecimento do aluno-monitor.

Para tanto, Cordeiro e Oliveira (2011) ressalvam que ser monitor compete, em suas exigências, o aperfeiçoamento do aluno, uma vez que ele não pode falhar de forma repetitiva, no compromisso de auxiliar os monitorados, na compreensão do que lhes é passado em sala de aula.

Quanto às colocações dos orientadores sobre as atribuições e responsabilidades, as respostas também foram unânimes, onde todos ressaltaram ter clareza a respeito de suas funções. As atividades consideradas como próprias da orientação da monitoria, apresentada pelos sujeitos, estão voltadas para um acompanhamento realizado junto aos monitores, de modo que os possibilitem a melhor desenvolverem essa prática que é de grande valia no ensino da graduação. A seguir, são destacados os registros.

Sim. A direção de ensino realizou reuniões onde explicou para orientadores e monitores seus direitos e deveres em relação a monitoria. A orientação da monitoria acadêmica inclui, entre outras, as responsabilidades de: zelar pela eficiência no desenvolvimento das atividades do estudante monitor previstas no plano de trabalho; realizar reuniões periódicas com o estudante 
monitor de forma a discutir melhorias no seu processo de monitoria [...]; informar previamente o cronograma da disciplina pela qual o aluno é monitor, de forma que o mesmo possa se preparar para auxiliar nas aulas práticas, visitas técnicas e tirar dúvidas dos discentes com planejamento prévio. $\mathrm{O}_{2}$

Sim. Dar autonomia ao aluno para ajudar no planejamento das atividades da disciplina, dentro daquilo que foi conversado inicialmente e fazer o acompanhamento do que se adequa efetivamente às questões pedagógicas da disciplina. 03

Sempre tive clareza [...]. As atribuições voltadas para orientação deveriam ser o acompanhamento do monitor em sua formação com os conteúdos da disciplina, identificar junto com o monitor as principais dificuldades dos alunos durante os atendimentos, verificar a frequência dos alunos nos atendimentos e elaborar estratégias para abranger o maior número de alunos possível, principalmente aqueles com maior dificuldade. $\mathrm{O}_{4}$

Os relatos dos orientadores aqui destacados corroboram com aquilo que Pereira (2007) enfatiza, ao considerar que o professor, nas atividades de monitoria, é tido como mediador dos conhecimentos, determinando uma relação entre os conhecimentos específicos e a prática pedagógica. Dentre as atribuições do orientador, ressalta-se o acompanhamento sistemático das atividades exercidas pelo monitor, elaboração do plano de atividades semestral em conjunto ao monitor, organização do horário de trabalho, assegurando o cumprimento da carga horária exigida pelo programa e garantindo ao monitor a assistência necessária para o cumprimento das atividades previstas nos conteúdos programáticos.

Ademais, torna-se relevante reforçar que o professor orientador deve buscar agregar novas técnicas de preparação, dentro da realidade da monitoria, de modo que os monitores sejam desafiados a moldar suas responsabilidades para com a prática pedagógica.

Para Nunes (2007), ao interagir com a sala de aula, o monitor poderá se encarregar de exercer atividades de auxílio aos alunos, nas práticas de laboratórios ou em outras atividades que o professor lhes atribuírem. E, melhor seria, se o professor destinasse um espaço da aula, como sendo de responsabilidade do monitor, claro, quando o mesmo estiver preparado para isso, apresentando alguma inovação que tenha encontrado, relatando uma experiência etc. Assim, conforme o planejado, o monitor teria seus momentos de responsabilidade durante a execução da aula, supervisionada por seu orientador.

O registro de um dos orientadores enfatiza bem a ideia supra, em que destaca para as atividades próprias da orientação o ato de colocar o aluno monitor para vivenciar experiências desafiadoras, notando-se a importância destas para a qualificação profissional futura do monitor. A seguir, expõe-se tal registro.

Fazer o aluno monitor vivenciar desafios e dificuldades que possivelmente irá enfrentar na atuação profissional futura. Fui monitor na época da faculdade de uma disciplina que lecionei anos depois 
no IFCE. A experiência prévia me ajudar bastante a fazer o correto planejamento da disciplina. 01

Assim, constata-se que a monitoria permite ao aluno monitor adquirir saberes necessários que qualificam a prática docente, posto que será capaz de desenvolver diversas habilidades que vão desde a capacidade de interação, até ao saber comportar-se em determinadas situações, tanto na vida acadêmica, quanto na profissional (SILVA; BELO, 2012).

De modo geral, conforme os registros apresentados e a literatura analisada, podese observar que as atividades de orientação da monitoria se apresentam de forma sistematizada, agregadas aos conhecimentos decorrentes das experiências dos docentes e repassadas aos monitores para que estes desenvolvam suas próprias práticas pedagógicas.

\section{Categoria Temática 3 - Experiências significativas, vivenciadas por monitores e} orientadores, no decurso da monitoria acadêmica.

Nesta categoria temática são analisadas as colocações dos sujeitos sobre suas experiências, durante o programa de monitoria, em que se expressam as que produziram maior significância. Da análise, é possível observar as contribuições do referido programa, no aprendizado, com destaque para o uso de diferentes metodologias, sendo o acesso e a aplicação destas, de modo geral, aquilo que se revela como de mais marcante. A seguir, são apresentados os registros.

A experiência mais relevante que tive como monitora foi o aprendizado meu e dos meus colegas quanto a uma disciplina que considerávamos complicada, melhorando o desempenho acadêmico no geral, através de metodologias lúdicas, bem como as amizades adquiridas no decorrer das atividades. $M_{3}$

Como experiência boa, posso citar a ideia de criar charadas para estimular os alunos a recordarem e aprenderem o conteúdo e a proposta ter sido bem aceita por eles, foi um fator que marcou muito. Sempre é muito bom propor uma metodologia que é bem aceita na turma [...]. M4

Cada orientação de monitoria é uma experiência interessante, pois cada aluno traz novidades $e$ ideias interessantes para as disciplinas e facilitação do aprendizado dos alunos que ajudam a nós docentes a repensar e melhorar as disciplinas. Uma que achei muito interessante foi a realização de uma disputa de perguntas promovida pelo meu monitor anterior de zoologia II [...] Achei muito divertida e interessante a proposta, pois foi idealizada e realizada pelo próprio estudante, com 0 meu aval e supervisão, e a adesão e feedback dos discentes foi muito positiva. $\mathrm{O}_{2}$

A experiência mais significativa foi a melhora no rendimento de alunos que buscaram na monitoria uma alternativa para uma melhor compreensão do conteúdo e ter êxito na disciplina. Destaco também, os alunos monitores que passaram a compreender melhor os conteúdos da disciplina na qual atuaram. $\mathrm{O}_{4}$

A utilização de metodologias que buscam auxiliar na melhor assimilação do conteúdo é fundamental para o processo ensino-aprendizagem, pois, além de tornarem as aulas mais atrativas, o que favorece o aprendizado dos educandos, facilita ao professor 
para que este, durante a explanação da aula, possa produzir efeitos positivos no ensino da graduação em geral.

Para Nicola e Paniz (2016), quando se utiliza um recurso que produz resultados satisfatórios, o aluno possui mais segurança, o que o torna apto a buscar por novas situações de aprendizagem e de construir conhecimentos mais complexos. Os autores ainda ressaltam que o aprendizado se torna mais considerável à medida que se utiliza de diferentes recursos para auxiliar o ensino, podendo assim contextualizar os conteúdos abordados pelo professor, permitindo aos discentes a ampliação dos conhecimentos já adquiridos ou a construção de novos conhecimentos.

Dentro da prática da monitoria, como sendo o acadêmico monitor responsável por promover a mediação entre o professor e os alunos nas atividades de ensino, 0 aprendizado torna-se mais significativo. O monitor, por se apresentar na mesma situação acadêmica que os demais, poderá contribuir não só com as dificuldades como um todo, mas será capaz de ser um pouco mais sensível com os diversos problemas que o estudante poderá enfrentar em períodos de avaliações e nos demais trabalhos, bem como em finais de semestres. Assim, desde que haja uma preparação, o monitor conseguirá ajudá-los, intervindo diretamente nestas situações e, em conversa com o professor, poderá discutir os problemas (NATARIO; SANTOS, 2010).

Contudo, o que deveria ser uma atividade de apoio aos alunos, em alguns casos, se não entendida assim, pode se tornar uma prática exploratória. Isto pode ser atestado no registro do $\mathrm{M} 4$, a seguir, que relata algo desagradável neste sentido.

[...] Como experiência não tão boa, acredito que foram as reuniões de revisão de conteúdo que os alunos agendavam horas antes da prova. Nesses momentos, muitas vezes eu via que os alunos não haviam estudado e esperavam que eu pudesse sintetizar todo o conteúdo para que eles pudessem ter um bom desempenho. Fiquei triste porque esses encontros acabavam não sendo tão produtivos como poderiam ser se os mesmos estivessem revisados os conteúdos. Mas, de toda forma, me permitiu aprender a sintetizar minhas explicações e melhorar minha transposição didática. M4

Considerando o registro anterior, pode-se perceber que os momentos de monitoria nem sempre produzem as melhores experiências. Nestes casos, elas podem estar associadas ao não cumprimento, pelos alunos, dos seus deveres e obrigações discentes, esperando que o monitor possa entregar algo pronto e acabado em relação ao processo de aprendizagem. Ao mesmo tempo, ainda que diante destas situações tensionadas, prevalecem as boas oportunidades de aprendizado para o monitor, uma vez que o imprime a necessidade de melhor organização, aprofundamento de saberes e diversificação das suas formas de abordagem, com o intuito de produzir melhor transposição didática e, consequentemente, se alcançarem melhores desempenhos dos alunos.

Evidentemente, isso contribui de forma positiva para qualificação do monitor como futuro professor, posto que para ensinar é preciso saber ir além do conceito de 
"abordar" o conteúdo. Segundo Fonseca (2008), ser professor não é só repassar o conteúdo, realizar exercícios e elaborar provas. É preciso ir além dessas limitações e buscar utilizar de meios que contribuam e favoreçam no processo de construção do aprendizado.

Categoria Temática 4 - Possíveis dificuldades e/ou problemáticas enfrentadas com as experiências vivenciadas

Nesta categoria, expõem-se as principais problemáticas apresentadas pelos monitores e orientadores durante suas vivências no programa, permitindo-se notar um descontentamento, por parte dos envolvidos, especialmente em função da infrequência dos alunos, na busca da assistência da monitoria, repercutindo na fragilização das suas potencialidades para a melhoria do ensino e aprendizagem. A seguir, apresentam-se alguns dos registros que podem atestar o que está sendo posto.

Não diria dificuldade, acredito que a proposta poderia apresentar um resultado melhor se houvesse um maior envolvimento dos alunos com o programa de monitoria e se a instituição pudesse fomentar financeiramente os bolsistas de modo que os permitisse se dedicar melhor à monitoria. M4

A falta de procura pela monitoria por parte dos discentes, assim como, a falta de incentivo $e$ divulgação por parte do professor da disciplina para os alunos. Muitas vezes, no meu horário de monitoria, eu ficava estudando algo pessoal ou algo sobre a disciplina da monitoria, porque ninguém me procurava nos meus horários [...]. M5

Vejo apenas duas dificuldades no processo de monitoria até hoje: a falta de bolsa para os monitores, o que limita o número de participantes, já que nem todos podem dispor de um horário para trabalho não remunerado, e a baixa adesão dos discentes das disciplinas no decorrer dos semestres nos horários de monitoria (com exceção dos dias antes da prova, quando então o monitor é bem procurado. 02

A maior dificuldade do programa de monitoria é a adesão dos alunos, que necessitam desse suporte fora da sala de aula, mas não o buscam com a frequência adequada. Os alunos precisam de uma maior conscientização desse espaço e de sua importância na melhoria do processo de ensinoaprendizagem. $\mathrm{O}_{4}$

De fato, Silva e Belo (2012) ressaltam que em certas ocasiões as atividades de monitoria, desenvolvidas dentro das universidades, são pouco aproveitadas por parte de alguns alunos que desprezam esta prática, dispensando o suporte didático o qual é ofertado como subsídio para o desempenho acadêmico. Outros estudos confirmam esta desvalorização, por parte dos alunos, a exemplo de um estudo realizado no Instituto Federal do Ceará, Campus Sobral. O referido estudo comprova o desconhecimento, de alguns alunos, acerca das atividades realizadas pelo monitor e destaca a possibilidade de afetar negativamente a formação dos alunos, uma vez que eles se privam de buscar por melhorar seu desempenho no curso, através de uma prática que oferece recursos que muitas vezes não é oferecido pelo professor (NETO; PARENTE; FRAGA, 2019). 
Assim, é importante que os alunos revejam seus posicionamentos em relação as práticas que subsidiam o processo de aprendizagem. Quando o estudante desfruta dos serviços oferecidos pelo monitor, ele se mostra como um sujeito interessado e que valoriza a construção do seu conhecimento, aproveitando as oportunidades que as instituições de ensino oferecem (SILVA; BELO, 2012).

Ressalta-se, portanto, a importância que o programa da monitoria exerce, em função da melhoria do desenvolvimento acadêmico. Isto pode ser comprovado a partir dos registros dos sujeitos, em que se atesta a forma como a monitoria repercute, significativamente, no processo ensino-aprendizagem, destacando o quanto esta prática é enriquecedora para os que dela participam.

A troca de conhecimentos e experiência entre o monitor e alunos é enriquecedor para os dois lados, pois trata-se de uma relação de ensino-aprendizagem mais "estreita", entre um aluno que já teve aquela experiência de aprendizagem e com alunos que estão vivenciando pela primeira vez. M1

É uma maneira de auxiliar até mesmo os alunos que são mais tímidos, que não conseguem tirar suas dúvidas na hora da aula devido à vergonha. Assim, permite trazer o aluno para mais perto da disciplina, uma vez que os professores não possuem tempo extra suficiente para atender todos os alunos em outros turnos, devido a quantidade de aulas que eles precisam ministrar. M8

Uma vez que temos a possibilidade de sedimentarmos o conhecimento adquirido, a possibilidade de o aluno conhecer melhor sobre os temas e aprender o conteúdo, faz com que tenham a capacidade de fixar melhor a disciplina ministrada. $\mathrm{O}_{5}$

O aluno monitor reforça os conteúdos abordados em sala de aula, utilizando muitas vezes uma didática mais acessível à realidade do aluno em atendimento. Destaca-se também o atendimento de forma direta a aqueles alunos com maior dificuldade em assimilar os conteúdos, trabalhando exatamente nas causas. $\mathrm{O}_{4}$

Para Antunes et al. (2016), à medida que ocorre o avanço do semestre, consequentemente, as disciplinas se mostram cada vez mais complexas. Logo, esta realidade vivenciada pelos discentes reforça à necessidade de lhes ser exercida uma assistência mais individualizada, podendo esta ser desempenhada através da participação dos monitores.

Silva et al. (2017) ressalta que a monitoria, além de possibilitar que os conhecimentos aprendidos em sala de aula tenham um maior aperfeiçoamento, permite obter um trabalho conjunto entre estudantes e docentes, de modo que as dificuldades no aprendizado sejam minimizadas e assim se contribua para um bom resultado escolar.

Dessa forma, as atividades de monitoria refletem algo bastante positivo na formação do aluno, especialmente na formação profissional do aluno monitor, permitindo, assim, que sua construção seja fortalecida à medida que são proporcionadas as mais diversas vivências no contexto acadêmico (CHAVES; BARBOSA; THERRIEN, 2017).

Mediante as concepções dos envolvidos na pesquisa, as contribuições que a 
monitoria pode conferir à formação, enquanto discente e docente, estão relacionadas ao processo de construção e aperfeiçoamento do aprendizado, de modo que lhes permitam um melhor desenvolvimento de suas práticas.

Acredito que domínio da disciplina da qual fui monitor, polimento da minha habilidade de transposição didática, maior conhecimento sobre os fatores que regem o processo de ensinoaprendizagem, além de me proporcionar uma experiência didática com uma turma de ensino superior. $\mathrm{M}_{4}$

Saber relacionar melhor a teoria com a prática, ter uma melhor postura em sala de aula, conhecer melhor o mundo laboratorial, ter experiências em aulas práticas, conseguir repassar com exatidão os conteúdos estudados, adquirir mais conhecimento sobre os temas abordados em sala de aula, dentre vários outros. M7

Me ajudou, acima de tudo, a fazer um melhor planejamento das minhas aulas e das minhas atividades. 01

O de refletir sobre as práticas pedagógicas. $O$ aluno quando conversa, dá ideias, também nos faz refletir sobre nossas prática. 03

Os relatos apresentados anteriormente podem reforçar que a monitoria é tida como de grande valor, nas diferentes dimensões, pois de um lado atua como contribuidora na melhoria do ensino, e de outro se mostra como um espaço de formação tanto para o monitor, quanto para o professor orientador (BELO; FARIA, 2015).

Para tanto, o significado da monitoria vai muito além da obtenção de um título, posto que existem diferentes aspectos que excedem tal conquista, a exemplo disto é o ganho intelectual do aluno monitor, sua contribuição dada aos alunos monitorados, bem como a troca de conhecimentos decorrente da relação entre os professores da disciplina e o monitor (MATOSO, 2014).

\section{Considerações Finais}

Ao nos depararmos com os resultados desta pesquisa, entendemos que seu objetivo foi alcançado, na medida em que nos foi conferida a oportunidade para analisar, sob a perspectiva dos envolvidos com a monitoria acadêmica (monitores e orientadores), no Curso de Licenciatura em Ciências Biológicas do IFCE/Campus Acaraú, o significado que estes atribuem ao referido instrumento de formação.

A partir dos achados, infere-se que a monitoria acadêmica tem reflexos significativos no processo de ensino-aprendizagem, mas que, para o alcance máximo do seu potencial formativo, lacunas precisam ser sanadas em se tratando de experiências desenvolvidas no campo da formação inicial.

A totalidade dos pesquisados compreende a monitoria como uma importante ferramenta de contribuição no processo de ensino e aprendizagem durante a graduação 
que, como consequência, fortalece a experiência formativa de monitores para o exercício da docência.

Foi amplamente reforçada a ideia que, quando em período de atividades da monitoria, o aluno monitor poderá estar vivenciando diferentes realidades do seu cotidiano de formação e de forma antecipada poderá experimentar os primeiros "prazeres" e "contratempos" da sua futura profissão.

Do mesmo modo, ao tempo em que esses monitores desenvolvem habilidades inerentes ao contexto da ação docente, fortalecem sua formação para esta área de atuação profissional e colaboram com o aprendizado de seus pares.

Observou-se, portanto, que as atividades desenvolvidas durante o programa da monitoria estiveram, de fato, voltadas para o favorecimento do processo ensino e aprendizagem. No entanto, como dito anteriormente, ainda foi possível perceber a necessidade apontada para maior valorização deste programa, no sentido de ser mais procurado pelos alunos que necessitam de um maior acompanhamento, o que poderia Ihes proporcionar melhores resultados no que tange ao desenvolvimento educacional e curricular durante o curso de licenciatura.

Portanto, os resultados deste estudo apontam para a importância do fortalecimento da monitoria acadêmica em âmbito institucional, na perspectiva de que possa ser fomentada em todo o contexto da formação inicial.

\section{Referências}

ANTUNES, S. S. et al. A importância do monitor para o processo de formação acadêmica, otimizando o aprendizado. In: Congresso Internacional de Educação Inclusiva, 2., 2016, Campina Grande: Anais [...]. Campina Grande, 2016. p. 1-5. Disponível em: https://www.editorarealize.com.br/index.php/artigo/visualizar/22570. Acesso em: 08 fev 2020.

BARBOSA, M. G.; AZEVEDO, M. E.; OLIVEIRA, M. C. A. Contribuições da monitoria acadêmica para o processo de formação inicial docente de licenciandas do curso de Ciências Biológicas da FACEDI/UECE. In: ENEBIO E II EREBIO REGIONAL, 5., 2014. Anais [...]. São Paulo, 2014 p. 5471-5476.

BELO, V. M. G.; FARIA, S. C. Estudo do programa de monitoria desde a sua fundação até sua implementação no curso de Direito da Universidade Estadual de Mato Grosso do Sul. In: Simpósio Científico-Cultural (SCIENCULT), v. 6, n. 1, 2015, Paranaíba. Anais [...]. Paranaíba, 2015. p. 153-166.

CAVALCANTE, S. S. et al. Monitoria de biologia - ferramenta auxiliadora no processo de ensino e de aprendizagem. In: Congresso Nacional de Educação, 4., 2019, João Pessoa.

Anais [...]. Campina Grande, 2019. p. 1-5. Disponível em: https://www.editorarealize.com.br/index.php/artigo/visualizar/61149. Acesso em: 09 Dez. 2019 .

CHAVES, M. J. C.; BARBOSA, E. S.; THERRIEN, S. M. N. Influência da monitoria acadêmica 
na formação do ser docente na enfermagem: um relato de experiência. Revista COCAR, Belém, v. 11. n. 22, p. 202-227, jul./ dez. 2017.

CORDEIRO, A. S.; OLIVEIRA, B. P. Monitoria acadêmica: A importância para o aluno de licenciatura em química. In: Encontro de Ciência e Perícia Forenses do RN, 2., 2011, Natal. Anais [...]. Natal: ANNQ, 2011. p. 1-5.

DIAS, A. M. I. Ser professor(a) universitário(a): monitoria, política e programas institucionais de formação docente. In: Encontro Nacional de Didática e Práticas de Ensino - ENDIPE, 16., 2012, Campinas. Anais [...]. [S. I], 2012. p. 2-12.

FONSECA, T. M. M. Ensinar X Aprender - Pensando a prática pedagógica. PONTA GROSSA - PR: Secretaria de Estado da Educação, 2008.

GALDINO, E. T. S.; ABRANTES, K. N. F. C. DESAFIOS DA MONITORIA ACADÊMICA: PERCEPÇÃO DOS ALUNOS MONITORES E MONITORADOS. Encontro de Extensão, Docência e Iniciação Científica (EEDIC). [S. I.], v. 5, n. 1, mar. 2019. Disponível em: http://publicacoesacademicas.unicatolicaquixada.edu.br/index.php/eedic/article/view/306 1/2620. Acesso em: 08 jan. 2020.

GIL, A. C. Como classificar as pesquisas? In: GIL, A. C. Como elaborar projetos de pesquisa. 4. ed. São Paulo: Atlas, 2008. Cap. 4, p.41-56.

LIRA, M. O. et al. Contribuições da monitoria acadêmica para o processo de formação inicial docente de licenciandos em ciências biológicas da UEPB. In: Congresso Nacional de Educação, 2., 2015, Campina grande. Anais [...]. Campina Grande, 2015. p. 9. Disponível em: https://editorarealize.com.br/artigo/visualizar/15677. Acesso em: 09 fev. 2019

LÜDKE, M.; ANDRÉ, M. E. D. A. Pesquisa em educação: abordagens qualitativas. 2 ed. Rio de Janeiro: E.P.U., 2013.

MATOSO, L. M. L. A importância da monitoria na formação acadêmica do monitor: um relato de experiência. Catussaba: Revista Cientifica da Escola da Saúde-UNP, Natal, Ano 3, n. 2, p.77-83, abr./ set. 2014.

NATÁRIO, E. G.; SANTOS, A. A. A. Programa de monitores para o ensino superior. Estudos de Psicologia, Campinas, 27(3)., p. 355-364, jul. / set. 2010. Disponível em:

https://www.scielo.br/j/estpsi/a/VNy8x9W5st93VFJ7Lcs9RjP/?lang=pt. Acesso em: 08 Jan 2020.

NETO, J. G. P.; PARENTE, N. N.; FRAGA, W. B. Uma análise das concepções discentes acerca da monitoria no curso de Licenciatura em Física no IFCE. Rev. Docência Ens. Sup, Belo Horizonte, v. 9, p. 1-16, 2019. Disponivel em:

https://periodicos.ufmg.br/index.php/rdes/article/view/2587. Acesso em: 09 Dez 2019.

NEVES, J. L. Pesquisa qualitativa - Características, usos e possibilidades. Caderno de Pesquisas em Administração, São Paulo, v. 1, n. 3, p. 1-5, 1996.

NICOLA, J. A.; PANIZ, C. M. A importância da utilização de diferentes recursos didáticos no ensino de biologia. InFor, Rev. NEaD-Unesp, São Paulo, v. 2, n. 1, p. 355-381, 2016.

NUNES, J. B. C. Monitoria acadêmica: espaço de formação. In: (Orgs.). - Natal, RN: EDUFRN - Editora da UFRN. Coleção Pedagógica, n. 9, p. 45-57, 2007.

PEREIRA, J. D. Monitoria: uma estratégia de aprendizagem e de iniciação à docência. In: 
(Orgs.). Natal, RN: EDUFRN - Editora da UFRN. Coleção Pedagógica, n. 9, p. 69-80, 2007.

RABELO, I. D. M. et al. Monitoria em psicologia: Uma experiência acadêmica. Caderno De Graduação - Ciências Humanas e Sociais, Alagoas, v. 3, n. 3, p. 157-168, nov. 2017.

SILVA, I. A. M. et al. Monitorias: atividade acadêmica que contribui para a permanência e êxito dos estudantes no IFTM Campus Ituiutaba. In: MARTINS, A. P. et al. (org.). Processos e práticas de ensino no IFTM: o acesso, a permanência e o êxito dos estudantes. 1. ed. Uberaba-MG: IFTM, 2017. cap. 1, p. 13-28.

SILVA, R. N.; BELO, M. L. M. Experiências e reflexões de monitoria: contribuição ao ensino-aprendizagem. Scientia Plena, Aracaju, n. 7, v. 8, p. 1-6, jul. 2012. Disponível em: https://www.scientiaplena.org.br/sp/article/view/822/553. Acesso em: 09 dez. 2019.

SOUZA, R. O.; NERY, V. S. C. Formação para a docência no ensino superior: Estudos sobre os saberes docentes e programas de monitoria. MARGENS - Revista Interdisciplinar, [S. I.], vol. 10. n. 14. p. 75-94, jun, 2016. Disponível em: https://periodicos.ufpa.br/index.php/revistamargens/article/view/4250/0. Acesso em: 09 fev. 2019.

STEFANELLO, F.; JUNIOR, M. L. J.; BEATRICI, A. F. A monitoria acadêmica com estudantes do ensino técnico e a intervenção na aprendizagem. In: Seminário de Educação, Tecnologia e Sociedade, 22., 2017, Taquara. Revista Redin, [S. I.], v. 6, n. 1. p. 11, 2017. 